\title{
The issue 'Raw milk quality' from the point of view of a major dairy industry
}

\author{
H.J. Andersen ${ }^{1}$ \\ Arla Foods a.m.b.a. \\ Skanderborgvej 277, DK-8260, Viby J., Denmark
}

\begin{abstract}
The mission of Arla Foods is to provide modern consumers with milk-based products that create inspiration, confidence and well-being. Consequently, Arla Foods continuously needs to obtain and implement all necessary knowledge of relevance for controlling the quality of our products.

The ongoing dramatic changes in the international market place, caused by global changes in lifestyles and requirements of consumers, require high standards of quality assurance regarding diversity, quality and safety of products and the environmental, ethic and animal welfare aspects of the food production. Consequently, the need for inclusion of the whole food production chain to develop strategies for production of foods with high quality has never been more urgent.

Even though raw milk quality has always been a cornerstone for Arla Foods, the above-mentioned requirements of the modern consumer request a constant expansion of our raw milk quality concept of a major dairy industry towards issues of importance for the consumers. Thus, raw milk quality cannot contain only quality characteristics that just meet statutory quality requirements and quality characteristics of importance for the settling price of the dairy farmers.

Consequently, Arla Foods has recently implemented a quality assurance programme called Arlagården, which includes quality requirements compatible to those that also satisfy consumer demand for "soft" values, i.e. the consumers can be assured that Arla Foods is consistently concerned with the proper exploitation of resources, the environment, animal welfare, ethics etc. throughout the entire production process.

Nevertheless, Arla Foods will continuously need to obtain new knowledge to expand the raw milk quality term as our fulfilment of the company mission is continuously challenged by new demands from our costumers including the modern consumer. This calls for strategic multidisciplinary research of importance for raw milk quality, which can further improve quality assurance programmes for raw milk production in the years to come. This includes research, which additionally can 1. develop sustainable management systems, 2. make nutrigenomics in relation to animal health functional in management decision systems, 3. combine raw milk composition and human health, 4. improve milking systems, handling and storage of raw milk, 5. improve hygienic design at the modern milk farm, 6. develop simulation models of importance for developing effective hazard analysis critical control points (HACCP) concepts, and finally, 7. develop robust and sensitive in-
\end{abstract}

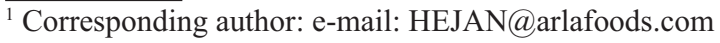


and at-line methods including microbial rapid methods applicable at all stages of the milk chain. These areas of research are briefly described in relation to the urgent needs of a major dairy company of tomorrow.

KEY WORDS: raw milk quality, consumer, traceability, sustainability, animal welfare, nutrigenomics

\section{INTRODUCTION}

There are dramatic changes in the international market place, caused by global changes in lifestyles and requirements of consumers. These changes require high standards of quality assurance regarding diversity, quality and safety of products and the environmental, ethic and animal welfare aspects of the food production. Consequently, the need for inclusion of the whole food production chain to develop strategies for production of foods with high quality has never been more urgent.

Especially, the quality of raw material of bovine origin has during the past years become an increasing issue for the consumers. This is due to the recent deplorable incidents in the dairy sector like bovine spongiform encephalopathy (BSE), verotoxigenic E. coli (VTEC), chronic wasting in cattle, and recall of antibiotic-containing consumption milk. Moreover, outbreaks of various diseases in Europe like foot-and-mouth disease have induced public concern about the way that husbandry animals are kept and transported. From a European policy point of view, the European Food Safety Authority, EFSA has launched Regulation (EC) No 178/2002 (http://eur-lex.europa.eu/LexUriServ/site/en/oj/2002/1_031/1_ 03120020201en00010024.pdf), and the recent EC Action Plan on the Protection and Welfare of Animals 2006-2010 (http://ec.europa.eu/food/ animal/welfare/ actionplan/actionplan_en.htm), which both emphasizes the need to monitor farms for food safety, public health, animal health and welfare. These state that major dairy industries no longer can rely on only the classic technology e.g., milk cell count, bacterial counts, antibiotic residues, freeze point decrease, protein and fat content and sensory quality measures in the development of tomorrow's quality concepts.

In Scandinavia, quality management programmes for bovine farm animals have been developed (Knudsen, 1997). In 2003 Arla Foods implemented a quality assurance programme called Arlagården, which includes quality requirements compatible to those that also satisfy consumer demand for "soft" values in the milk production (http://www.arlafoods.com/C1256E9400315C5D/O/CF0E82D2 08D8F774C12570F1004A0D67).

The programme comprises a clear description of the requirements, which the diary farmers are to satisfy, if they wish to deliver milk to Arla Foods. The programme state clearly which requirements originate from acts - for example the Danish Animal Feed Act or the Danish Act on the Protection of Animals, and which 
recommendations or requirements originate from the agricultural sector or from Arla Foods only. In this connection it is important to notice that the requirements in Swedish and Danish legislation are stricter than in most other countries. The programme specifies what type of documentation the diary farmer must be able to present. Moreover, Arla Foods can enforce sanctions if serious deficiencies are found on the farms. The sanctions can be fines, reduced milk prices or temporary milk collection stop until the deficiency has been rectified.

As mentioned above, the programme is based on the fact that the consumers of today wish to gain a much broader insight into the term food quality. Thus safety and complementary traceability as well as considerations regarding animal welfare and environment are now considered to be important parameters of quality on equal terms with milk composition, and are constantly developed in dialogue with all interested parties in the milk production chain (Figure 1). In Box 1 a brief description of these four quality parameters is given, as they are considered at present in the programme.

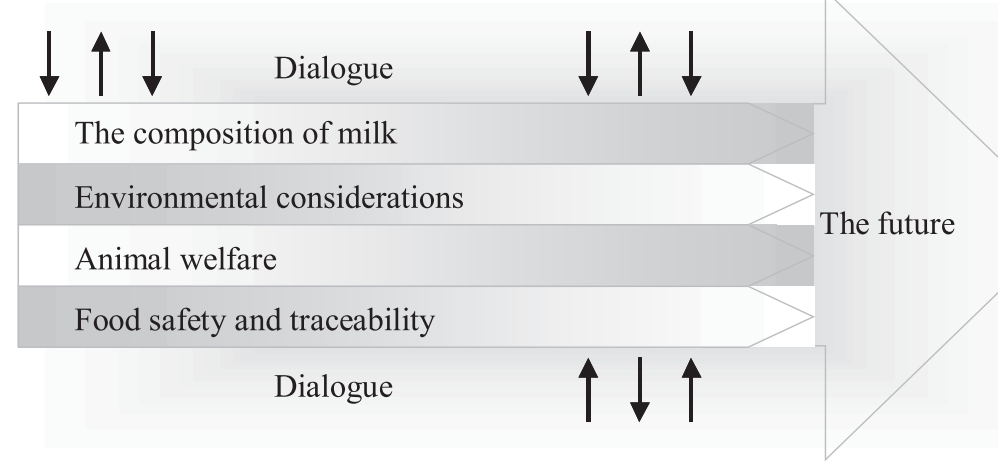

Figure 1. Presentation of the continuous development in milk quality parameters in a dialogue with interested parties

Naturally, Arla Foods also focuses very much on the taste, smell and raw material quality of milk. Therefore, the quality programme requires that cows are not given feed which may have a negative effect on milk taste, smell and quality.

Beside the above-mentioned "soft" quality characteristics, major dairy companies are constantly challenged on their production of new and diversified products, which contain stories, sensory diversity, nutritional benefits etc. Nevertheless, most major dairy companies have not yet explored the potential, which exists in differentiating raw milk with the exception of conventional and organic raw milk production. This is so despite the fact that it should be possible to introduce potential quality control tools into the primary production, and to make differentiated raw milk production with regard to taste, nutritional value and sustainability, etc. 


\section{Box 1}

Traceability

More than ever before, customers as well as consumers demand that products can be traced back to the producer in case of quality defects. Through the programme, traceability will become more visible in all respects:

- The origin of the feed appears from the invoices and delivery notes of the suppliers

- The requirements that milk producers must keep a pharmaceutical record state the medicine used

- Milk samples are taken continuously at each dairy farm

- By means of recordings it is possible to trace the diary farms on which the milk has been weighed in the tanker which has transported the milk, and the dairy to which the tanker has delivered the milk.

\section{Safety}

The milk production on farms, which supply milk to Arla Foods, must in every way take place under satisfactory conditions. Therefore, the quality programme is based on the precautionary principle. Safety requirements are given a high priority, and the key words are risk assessment and risk management.

In addition to the requirements of the legislation, the Arla Farm programme requires that:

- Cows must be fed high-quality concentrate from approved farm supply companies

- Roughage has not been cultivated on fields to which sludge has been applied

- A water analysis must be performed annually

- To avoid infectious diseases, live animals cannot be imported to the dairy farm

- On purchase of new milk bulk tanks, tank alarms are to be installed which sound an alarm at divergences and register the milk temperature and the cleaning process continuously

- The milking equipment must be cleaned after each milking, and the milk bulk tank must be washed after emptying

- The collecting area for the tanker must be kept clean and separated from the passage of the cows into and out of the cowshed

- To avoid infection, forty eight hours must pass between visits to foreign herds and subsequent contact with Danish or Swedish herds

- The milk are continuously tested for the content of somatic cells, bacteria, antibiotics and for visible changes.

\section{Animal welfare and environment}

Animals must be well kept, and the production methods must be respectful of nature o $\mathrm{n}$ the farms, which supply milk to Arla Foods. Subsequently, Arla Foods' animal welfare and environment requirements for milk producers are higher than the requirements of both the Swedish and Danish legislation, even though the legislative requirements of both Denmark and Sweden are high compared with other countries. Moreover, Arla Foods recommends that the dairy farmers join prophylactic animal health programmes. In order to use of nutrients. Furthermore, it is recommended that pesticides and insecticides are not used preventively but only when the acceptable thresholds of weed, disease and fungus damages have been exceeded.

http://www.arlafoods.dk/appl/HJ/HJ201AFD/HJ201CFG.NSF/AllGraphics/HBLL6KVH52/ \$FILE/BrochureArlagaarden_UK.pdf 


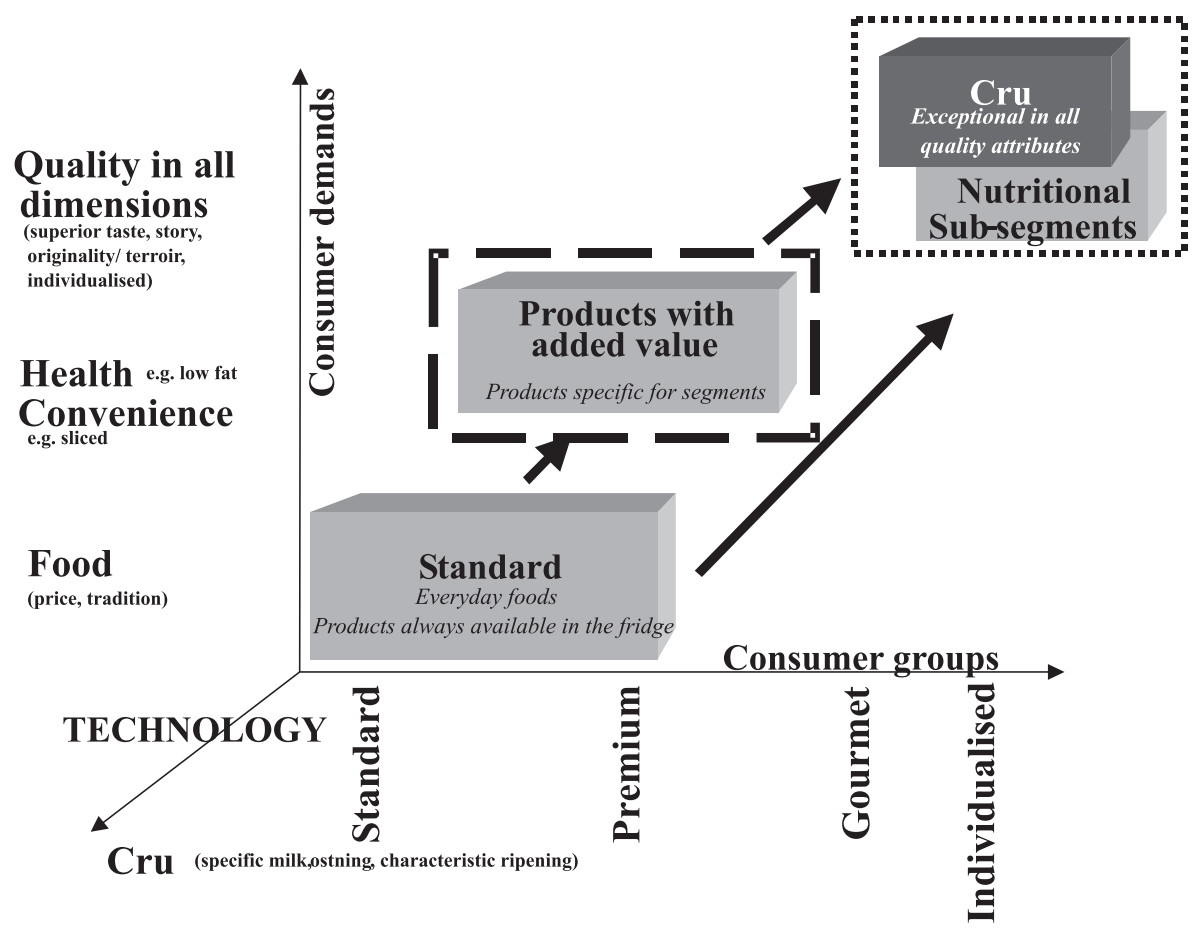

Figure 2 . The milk and dairy product market of tomorrow

Innovation at the dairy market is and will progressively be mainly customerdriven. Figure 2 gives a graphical representation of the possibilities in such a market. The standard segment will still dominate and represent the biggest milk tonnage and products that the consumers will always want to have in their fridge. However, the earning capacity of the dairy industry and hereby also the potential for a higher financial return to the milk producers, is in the segments represented by 'value-added products', 'cru products' and 'individualized nutritional products', which all need inclusion of values from the whole milk production chain.

Consequently, major dairy companies that include values from the whole food production chain and combine this with specific or new technological initiatives will without doubt be in a profitable situation. Niche production is a superior platform for subsequent expansion into the mainstream segments of local markets (Gupta and Govindarajan, 2000). However, before this becomes operational, scientific tools need to be developed to an operational level where they can contribute with new information and technologies to be included in tomorrow's quality assurance programmes supporting production of dairy products of high and diversified qualities. 
The present paper touches on some of those items, which need to be further developed before the dairy industry together with the scientific community and the dairy farmers can implement strategies and tools, which will make it possibly to continuously deliver dairy products demanded by the consumers of tomorrow.

\section{WHAT IS RAW MILK QUALITY?}

Quality is a philosophical made-up word introduced by Cicero - derived from the Latin word qualis, which means "how" or "of which character". This implies that quality can be translated to "how like" or characteristics (Barfield, 1988). However, this also implies that the term 'quality' is without meaning, if not defined. This is the reason why quality often can be interpreted differently, even though people declare to talk about the same issue. This difference in the interpretation is most often also evident in the discussion of raw milk quality. Thus if the milk producer has to define quality, he/she defines quality as good performance of his/her herd resulting in high yield and high fat and/or protein content maybe in combination with low cell number etc. which are the attributes the dairy pays him/her for. In the dairy industry the main quality attributes are optimal hygiene, superior oxidative stability, and good cheese making properties, as these attributes ensure production of valuable dairy products. Finally, the consumer considers safety, good taste, reasonable price, and healthiness to be among the main quality attributes.

The quality attributes demanded by customers/consumers are found to be the main driver of innovation of today (Anonymous, 2003), which is why the food industry including the dairy industry has approached product development from the view of 'Table to Farm' during the past years.

The demands from customers/consumers will increase continuously as a consequence of changes in socio-economic factors, further education, more ready and exposed information, etc. The milk quality concept is therefore a dynamic entity that will constantly include new quality attributes in addition to those already demanded by the modern consumer (Table 1). Consequently, there is a continuous need for readiness of action by the actors in the milk chain delivering products to costumers/consumers. Moreover, the scientific community has to support with the

Table 1. Milk quality attributes

\begin{tabular}{ll}
\hline & Quality attributes \\
\hline Safety & Traceability \\
Health & Animal welfare \\
Flavour & Animal feed \\
Appearance & Ethics \\
Convenience & Sustainability \\
Differentiation & etc. \\
Price & \\
\hline
\end{tabular}


necessary knowledge and tools, if the supply of milk and dairy products in Europe also is going to be financially feasible in the future.

\section{DOES THE SCIENTIFIC COMMUNITY FIT THE AIM OF SUPPORTING A MODERN RAW MILK PRODUCTION?}

It is interesting that the scientific community of importance for the agro/food industry in many industrialized countries is organized in separately applied disciplines animal/plant science, and food science and technology, etc. They hereby still representing a 'Farm to Table' approach, which historically was developed to support societies scarce on foods or economies purely driven by bulk production.

At the political level a 'Table to Farm' concept has been acknowledged as the approach of tomorrow's food production in Europe for more than a decade. Consequently, the funding bodies within EU have during the past decade continuously launched research programmes within the agro/food area, which include the 'Table to Farm' approach based on a customer/consumer-driven food production, having in mind the necessary change in the scientific community of importance for the agro/food industry. Nevertheless, the expected change in the scientific community of importance for the agro/food industry has only slowly started to take place during this period. Accordingly, the scientific community meant to support modern raw milk production is still far from fully developed to fulfil the demands needed to establish the basis that ensures that milk production in Europe is also financially profitable in the customer-driven sales environment of tomorrow. If the scientific community supporting a financially profitable milk production in the industrialized part of the world has to be fully operational, a rapid change from the 'Farm to Table' to the 'Table to Farm' approach needs to take place within a not too distant future. This calls for much more dialogue between scientific disciplines combining the traditional actors with consumer science, sociology, material science, human nutrition, system biologists, etc. It also requires a pronounced degree of multidisciplinarity in problemsolving and establishment of networks or platforms containing all the disciplines with focus on development of tools and solutions for a financially profitable milk production ruled by the demands of costumers/consumers.

\section{NECESSARY SCIENTIFIC INITIATIVES FOR THE MODERN RAW MILK PRODUCTION}

In the following are outlined some of the most urgent areas, which have to contribute with new and improved knowledge and tools in support of a modern and flexible raw milk production. However, also other areas not directed towards 
the quality of the raw milk and not mentioned in the following, need to contribute significantly to keep the milk production of tomorrow successful. This includes improved efficiency in the production, e.g., improved disease resistance, optimal fertility and reproduction, etc., together with especially educational initiatives so that increased competences and implementation of the obtained knowledge and technologies can ensure an optimal management at farm level.

\section{Optimal control of safety in the whole chain}

During the past twenty-five years, development of rapid methods has been a main topic in relation to improvement of and responds rapidly to safety issues of importance for food production. This has been necessary to develop appropriate safety control systems. Unfortunately the success has been limited. However, recent developments of biotechnological and nanotechnological tools together with progress within material science begins to bring about sophisticated Polymerase Chain Reaction (PCR) methods, cantilever systems, various microarray systems, new biosensors, etc. This substantiates an intensified research in new solid on-line/at-line methods, which can measure critical points throughout the milk production chain (e.g., feed, cow, raw milk, milk tank, throughout the processing chain, during storage and distribution with regard to pathogens, indicator organisms of contamination, antibiotics, toxins, chemical contaminants, allergens). Subsequently, this will support the development of hazard analysis critical control points (HACCP)-based quality management systems, where risk identification and prevention will play a paramount role.

Development of the above mentioned HACCP-based quality management systems as well as shelf-life prediction systems also calls for development of sophisticated modelling of growth and decline of pathogens, spoilers and contaminants in the milk and dairy products. These become the basis for the data needed for quantitative risk evaluations, which are the prerequisite for development of solid decision-making systems.

\section{Traceability}

Traceability is becoming one of the main quality attributes. Traceability is an extension of the safety attribute mentioned above. However, it also includes information regarding e.g., breed and identity of the animal, geographical origin, diet fed, animal welfare, processing technologies, etc. In addition to safety quality management systems, systems supporting traceability also demand further development and new initiatives within information technology. This is necessary to make it possible to obtain and store information throughout the milk production chain, which subsequently can be obtained by the consumer. At present Radio 
Frequency Identification (RFID) transponders seem to be a possibility. However, cheaper initiatives combining such technology with sensor technology, which automatically adds information throughout the production chain, e.g., timetemperature information, would be preferable in the future.

\section{Objective measurement of animal welfare}

Animal welfare is and will continuously be an issue of interest to the media and consumers and hereby also to the politicians in a society where the consumers are distanced from the practical animal production. Policy development in the area of animal husbandry continuously suggests that from the perspective of optimizing animal welfare, new management systems should be developed to provide opportunities for livestock animals to be raised in environments where they can engage 'natural behaviour' (Frewer et al., 2005). There is no doubt that animal welfare in the future will be a natural part of quality management programmes, which ultimately will result in HACCP-based quality-based management programmes including good farming practice. Such programmes in Europe have to fulfil the requirements set by e.g., the EU (Noordhuizen and Metz, 2005).

If dairy farmers have to be able to fulfil these challenges in the near future, objective measurements of animal welfare need to be developed and implemented at farm level.

During the past few decades the milk production from the individual cow has been multiplied. To ensure optimal welfare of all the animals in modern milk production, this demands a thorough understanding of especially the energy supply to the cow throughout the lactation period. At present this knowledge is far from appropriate. Accordingly, several of the animals are in energy/physiological unbalance, which reduces the overall welfare. This situation will unquestionably place the milk farmers and the dairies in the blaze of publicity, if this problem is not sought solved as rapidly as possible.

Considering that the bovine genome will be available within the next couple of years and that the omic-sciences and bioinformatics of today have entered a functional stage (Womack, 2005), it seems evident to take a nutrigenomic approach (Dawson, 2006) in solving problems regarding physiological unbalance of the modern milking cow. Such an approach will give biological markers, which subsequently can be used to control feeding. Moreover, in combination with the ongoing development within sensor technology, such an approach will also be able to ensure development of dynamic feed management systems and support implementation of HACCP-quality management systems including welfare at farm level. Finally, the information coming from such an effort will also have a generic value that likewise can be used in the optimization and control of health and welfare issues at farm level, as stressors independently of origin influence 
the physiological status of the animal directly. Consequently, an approach using nutrigenomics will in general contribute to the potential future establishment of documentation systems for 'the whole cow'. This will become a cornerstone for farmers and the dairy industry to convince the public of the ethics in modern milk production where effectiveness and industrialization dominate.

\section{Sustainability}

Sustainability in livestock farming necessitates both sociological and ecological aspects to be included when considering animal production development. The increasing public awareness of the impact of farming highlights the need for an improved understanding of such effects as well as the need for farmers to document and communicate the side effects of livestock farming to interested parties.

Sustainable milk production is already gaining importance in Europe, lead by organic milk production, where EU already has introduced regulations to standardize organic production throughout the member countries. Whether organic farming systems are more "environmental-friendly" than conventional management is not really the issue. The public has already made this decision, which is also gradually reflected in the products they demand. Consequently, development and documentation of sustainability becomes a main issue in the sale of milk and dairy products. The soil nutrient cycling, methane production and the energy consumption will be key indicators for developing more sustainable ruminant practices. However, also factors such as use of chemicals and antibiotics together with conservation of water will be important. Such a documentation of sustainability in milk production requests appropriate assessment tools. Different types of assessment tools are being developed with the purpose of determining the environmental impact of various livestock production systems at farm level (Halberg et al., 2005). However, the assessment tools need to be developed explicitly for milk production. Productoriented and life cycle-based environmental assessments technology (LCA) seems to be the most obvious methodologies because of the need to evaluate global emissions and impacts from the whole production chain in relation to types and amounts of products consumed. Likewise, such methodologies are also compatible with ongoing efforts regarding sustainability in the down-stream part of the production of milk and dairy products, e.g., the "Der Grüne Punkt" system (www:/gruener-punkt.de) concerning recycling of packaging material, which has shown marketing potential in Germany.

On a long view, sustainability will without a doubt be an integrated quality attribute, which also includes safety and animal health and welfare issues and hereby becomes a natural part of quality management systems at farm level. 


\section{Milk composition and integrity}

There is no doubt that increased and documented diversification of milk and dairy products is becoming a main issue in the years to come. Until now this diversification in modern milk production has almost been limited to milk coming from either conventional production systems or organic production systems. However, several of the main dairies have announced that they are going to market specific milk types in the near future.

Initially, these new milk types will focus on milk with diversified health properties, which as a minimum conform to dietary guidelines set forth by governmental agencies, and on the long view benefit human health in general. This is the first step in the renaissance of establishing milk as the preferred quencher of thirst, after nearly two decades, where the dairy industry has suffered from a bad health image due to a postulated 'wrong' fatty acid composition of the milk. However, recent scientific data show that this seems to be a wrong conclusion (Jacobsen et al., 2005; Huth et al., 2006). Some of the new biotechnological initiatives need to come into action to confirm the healthy aspects of milk, if milk has to regain its healthy reputation, and again become one of the preferred healthy thirst quenchers in many industrialised countries.

There is no doubt that the progress, which has taken place within genomics and other omic-sciences, together with the availability of both the human, and soon the bovine genome, will support a new access to milk derived nutritional research. Such an approach will use knowledge of the genes involved in lactation, the functions of milk-related genes, and the biology and physiology of milk consumption including comparative biology. This approach needs to be implemented to establish the basis for documentation of the healthiness of the different milk types produced according to the knowledge obtained in such an approach. Likewise, this approach has the potential to prepare the way for development of diversified milk and dairy products, which fulfil the needs for the individual, whether this is prevention of life style diseases or directly towards e.g., coronary heart disease, type 2 diabetes mellitus, inflammatory bowel disease, etc.

Milk flavour is another quality attribute, which is an obvious choice when different milk types are going to be diversified, as the consumer immediately recognizes this. To be able to differentiate raw milk with regard to flavour calls for a much better understanding of the influence of especially feeding on the composition of flavour active components in the raw milk. This again calls for a new and further understanding of the interaction of the feed with the microflora in the ruminant and eventually how wanted flavour components are protected in the rumen. Moreover, the interaction of breed effect on feed conversion in relation to flavour formation and development in the raw milk needs to be investigated much more into detail, and again the nutrigenomic approach mentioned above might be a possible tool to obtain such information. 
During the past decade the dairy technology has slowly moved into the farm to increase the effectiveness and the handling of the continuously larger herds at the individual farms without additional expensive manpower. This introduction of cooling tanks, automated milking systems (AMS), pumping equipment, cooling systems and extended piping systems requests a completely new understanding on how these systems should be installed, tuned and operated without affecting the quality of the raw milk. These new installations expose the milk to extensive physical stress at a rather high temperature, and this in combination with the subsequent cooling is known to be critical for especially the integrity of the milk fat globule. Moreover, introduction of such systems also increases the possibility for bio-film formation in new segments of the milk chain, and hereby it challenges the hygienic quality of the raw milk. However, at present this knowledge is scarce, and the introduction of these new initiatives at farm level has unfortunately already shown to give rise to milk quality problems (Abeni et al., 2005). Thus an intensive effort within this area is necessary to ensure the quality of the raw milk both with regard to milk flavour, technological quality of the milk and hygienic quality. Moreover, this effort needs to be supplemented with development of education modules, which can be supplied to the farmers, and hereby teach them to work these mini dairies at the farm.

Independently of the demands of the costumers/consumers, the raw milk production has to be financially effective. Consequently, the technological quality of the raw milk is of outmost importance, as the major part of the milk is used in the production of dairy products and ingredients. In most countries the dairies of today demand unitary milk, which not necessarily fulfil the optimal technological quality of all dairy products and ingredients. Accordingly, improving the manufacturing and processing of milk and dairy products using the potential tools in the primary production is another possibility in future milk production. Both genetics and feed are known to influence the technological quality of milk with the genotype being decisive for both protein composition/content and lipid content (Coulon, 2004). Feeding being decisive for lipid and vitamin/mineral composition together with the anti-oxidative status of the milk and to a lesser extent protein content (Jenkins and McGuire, 2006). However, at present the knowledge within this area is far from satisfactory, which is why an extensive effort is needed in the future. Likewise, the control of the nutritional value and of the technological quality of raw milk will without a doubt also benefit from introduction of a nutrigenomic approach in the elucidation of this challenge.

\section{NEW TECHNOLOGICAL TOOLS IN MODERN RAW MILK PRODUCTION}

Recent and ongoing advances in biomedical technology will assist in advancing our understanding of disease prevention and health promotion, as well as medical diagnostics and therapeutics (Ross et al., 2004). Likewise, these advances will 
also soon open the barn door and accelerate our understanding of identical aspects in relation to the milking cow considering the ongoing progress within livestock genomics (Womack, 2005).

These new, emerging technologies such as microarray technology and nanotechnology have the potential to advance nutrition and health science in many aspects of relevance for modern milk production, as mentioned above. This implies both a better understanding of the aspects of importance for ensuring the establishment of the conditions for the "whole cow" and hereby the necessary public acceptance of an effective and industrialised milk production, and the support of milk and dairy products as a natural part of a healthy diet.

Moreover, nanotechnology is meant to be a major driver in the 1. development of biosensors, 2. support of sustainable agriculture, 3. pathogen and contaminant detection, 4. improved animal health, e.g., through development of smart treatment delivery systems, and 5. material science and engineering, e.g., development of material with antibacterial activity and which is easy to clean (Kuzma and VerHage, 2006). These are all areas that can benefit from a modern raw milk production, as mentioned above.

The simultaneous development within information technology makes it already now possible to integrate all data obtained throughout the milk chain. Consequently, data obtained through existing devices in the milk chain in combination with new data coming from the future devices for data collection based on the above mentioned new emerging technologies would be a unique possibility to develop solid decision support systems at all levels in the future.

One of the big challenges in the implementation of these new technologies as rapidly as possible into the area of raw milk production is to establish networks and programmes that support interdisciplinary interactions between the traditional players within milk production, animal scientists and food scientists and human nutritionists, medical scientists and molecular biologists using the new technologies as connecting links. An excellent example of such an arrangement in relation to the biological complex is "The Milk Genomics Consortium" that emanates from University of California, Davis, and aims to develop a new approach to nutritional research (human and other species) that uses knowledge of the genes involved in lactation, the functions of milk-related genes, and the biology and physiology of milk consumption (German et al., 2006). However, many more initiatives are necessary, if modern raw milk production has to benefit from these new technologies. Both national and international governmental programmes with support from dairy associations and the dairy industry need to support the establishment and activities of such interdisciplinary networks, if the milk production has to fulfil the demands of the consumers and the public in the near future. 


\section{CONCLUSIONS}

The ever-increasing requirements of consumers and the public concern regarding sustainable food production in its widest sense have never challenged modern milk production more than today. Consequently, the main dairy industries need to include all aspects in the milk production chain to support a continuous profitable raw milk production. However, at present the scientific basis for developing a sustainable, flexible and diversified milk production that fulfils the requirements of the consumers and the public is not sufficiently strong.

As it is evident from above, optimal control of raw milk quality and development of solid decision support systems become extremely complex in a situation where both the consumers and the public interests have to be taken into consideration in a modern, profitable milk production. This requests that scientific advances including new and emerging technologies progress in the interaction between the more traditionally applied sciences of importance for an efficient milk production, e.g., animal science and food science and technology, and other areas, e.g., molecular biology, human nutrition, medical science, material science, advanced data handling and modelling, under the influence of consumer science and sociology in new networks and platforms.

The main scientific tasks in relation to modern milk production are to obtain an quantitative understanding of biological responses of importance for animal welfare and milk composition that substantiates the development of solid decision support systems and documentation and quantitative understanding of the nutritional value of milk in relation to communication and declaration of milk and dairy products.

\section{REFERENCES}

Abeni F., Degano L., Calza F., Giangiacomo R., Pirlo G., 2005. milk quality and automatic milking: fat globule size, natural creaming, and lipolysis. J. Dairy Sci. 88, 3519-3529

Anonymous, 2003. The power of customers to drive innovation. http://cordis.europa.eu/ innovationpolicy/studies/im_study $7 . h t m$

Barfield O., 1988. History in English Words. Great Barrington, MA: Inner Traditions/Landisfarne Press. Reprint of original 1953 Edition. Faber and Faber, London

Coulon J.B., 2004. Milk quality and cheese production: Effect of genetic and feeding on milk coagulation properties and on cheese sensory characteristics. $7^{\text {th }}$ Brown Swiss World Conference, Verona, pp. 55-65

Dawson K.A., 2006. Nutrigenomics: Feeding the genes for improved fertility. Anim. Reprod. Sci. 96, 312-322

German B.J., Schanbacher F.L., Lönnerdal B., Medrano J.F., McGuire M.A., MacManaman J.L., Rocke D.M., Smith T.P., Neville M.C., Donnelly P., Lange M., Ward R., 2006. International milk genomics consortium. Trends Food Sci. Technol. 17, 656-661 
Gupta A.K., Govindarajan V., 2000. Managing global expansion: A conceptual framework. Business Horizons 43 (2), 45-54

Frewer L.J., Kole A., Van den Kroon S.M.A., de Lauwere C., 2005. Consumer attitudes towards the development of animal-friendly husbandry systems. J. Agr. Environ. Ethics 18, 345-367

Halberg N., Van der Werf H.M.G., Basset-Mens C., Dalgaard R., de Boer I.J.M., 2005. Environmental assessment tools for the evaluation and improvement of European livestock systems. Livest. Prod. Sci. 96, 33-50

Huth P.J., DiRienzo D.B., Miller G.D., 2006. Major scientific advances with dairy foods in nutrition and health. J. Dairy Sci. 89, 1207-1221

Jacobsen R., Lorenzen J.K., Toubro S., Krog-Mikkelsen I., Astrup A., 2005. Effect of short-term high dietary calcium intake on 24-h energy expenditure, fat oxidation, and fecal fat excretion. Int. J. Obesity Relat. Metabol. Disord. 29, 292-301

Jenkins T.C., McGuire M.A., 2006. Major advances in nutrition: Impact on milk composition. J. Dairy Sci. 89, 1302-1310

Knudsen S., 1997. A quality and environmental management system developed by farmers. In: G. Schiefer, R. Helbig (Editors). Quality Management and Process Improvement for Competitive Advantage in Agriculture and Food. Proceedings of $49^{\text {th }}$ Seminar of the European Association of Agricultural Economists. Friedrich Wilhelms University, Bonn (Germany), pp. 131-135

Kuzma J., VerHage P., 2006. Nanotechnology in Agriculture and Food Production. Anticipated Applications. Woodrow Wilson International Center for Scholars, (http://nsrg.neu.edu/resources/ regulatory_capacity/documents/NanoAgFood.pdf), pp. 44

Noordhuizen J.P.T.M., Metz J.H.M., 2005. Quality control on dairy farms with emphasis on public health, food safety, animal health and welfare. Livest. Prod. Sci. 94, 51-59

Ross S.A., Srinivas P.R, Clifford A.J., Lee S.C., Philbert M.A., Hettich R.L., 2004. New technologies for nutrition research. J. Nutr. 134, 681-685

Womack J.E., 2005. Advances in livestock genomics: Opening the barn door. Genome Res. 15, 1699-1705 